\title{
Adverse effect of additional weight on exercise against gravity in patients with chronic obstructive airways disease
}

\author{
C R SWINBURN, B G COOPER, H MOULD, P A CORRIS, G J GIBSON \\ From the Department of Respiratory Medicine, Cardiothoracic Unit, Freeman Hospital, Newcastle upon Tyne
}

ABSTRACT The effects of an acute, artificially simulated increase in body weight on exercise performance were examined in 14 patients of normal weight (mean (SD) body mass index $22 \cdot 3(2 \cdot 7)$ ), age 61 (8) years) with chronic obstructive airways disease $\left(\mathrm{FEV}_{1} 1.2(0.5)\right.$; ; vital capacity (VC) 2.9 $(0 \cdot 6) 1$ ), and in six normal subjects with similar age and sex distribution. The patients performed a six minute walking test and a symptom limited step climbing test both with and without an additional $10 \mathrm{~kg}$ weight (two leaded aprons). The normal subjects performed a step test with and without the additional weight. Ventilation ( $\dot{\mathrm{V}} \mathrm{E})$ and oxygen consumption $\left(\dot{\mathrm{V}}_{2}\right)$ were measured during step climbing. Resting spirometric values were not altered by the additional weight. In the patients the median number of steps climbed fell from 67.5 when they were unweighted to 44.5 when they were weighted. Mean $\dot{\mathrm{V}}_{\mathrm{E}}$ and $\dot{\mathrm{V}}_{2}$ were increased during weighted step climbing by $14 \%$ and $13 \%$ but the maximum levels of $\dot{\mathrm{V}}_{\mathrm{E}}$ and $\dot{\mathrm{V}}_{2}$ achieved were similar during unweighted and weighted exercise ( $\dot{\mathrm{V}}_{\mathrm{E}}$ $36.8(8.6)$ and $37.3(10.2) 1 \mathrm{~min}^{-1}, \mathrm{VO}_{2} 1.35(0.3)$ and $1.41(0.4) 1 \mathrm{~min}^{-1}$ respectively). The normal subjects were readily able to complete 150 steps both with and without the additional weight. In the patients the six minute walking distance fell only slightly with the extra weight, from 554 (SD 61) to 540 (62) m. A subsidiary study was carried out in six healthy younger subjects in which $\dot{\mathrm{V}} \mathrm{E}$ and $\dot{\mathrm{Vo}}_{2}$ were measured during a $5.6 \mathrm{~km} / \mathrm{h}$ six minute treadmill walk at zero incline. The additional weight did not alter $\dot{\mathrm{VE}}$ or $\dot{\mathrm{V}}_{2}$ during exercise. In conclusion, a small acute increase in body weight substantially worsened the already reduced "uphill" exercise performance in patients with chronic obstructive airways disease because of its effect on ventilation and oxygen consumption. These results suggest that modest weight loss might benefit patients with chronic obstructive airways disease even though they may be only slightly above their ideal body weight.

\section{Introduction}

The main symptoms of patients with chronic obstructive airways disease are breathlessness and effort intolerance. Conventional pharmacological treatment attempts to lessen airflow obstruction and so improve these symptoms. In many patients such treatment produces only a small improvement in pulmonary function, so the patient remains chronically disabled. Although there have been attempts to treat the symptom of breathlessness specifically-for example, with codeine' or diazepam ${ }^{2}$ - the benefit, if any, has been slight and has not been seen in all patients.

Address for correspondence: Dr C R Swinburn, Musgrove Park Hospital, Taunton TA1 5DA. (Reprints will not be available.)

Accepted 13 June 1989
Although some patients with severe chronic obstructive airways disease-particularly those with emphysema - are thin, ${ }^{3}$ many remain above their ideal weight. The metabolic and ventilatory cost of exercise is increased by additional weight. ${ }^{4}$ In health obesity (unless extreme) does not limit normal day to day activity because there is considerable cardio- of respiratory reserve. By contrast, activity in patients $N$ with chronic obstructive airways disease is restricted N by the mechanical limitation to ventilation imposed by the disease. The presence of additional weight would therefore be expected to have a particularly adverse effect on exercise capacity in such individuals.

The purpose of this study was to measure the effects of a small, acute artificially induced increase in body weight on the ventilatory response to exercise and the exercise capacity of patients with chronic obstructive airways disease and of normal subjects. 


\section{Methods}

\section{SUBJECTS}

We studied 14 men with chronic obstructive airways disease of varying severity and six healthy subjects of similar age and sex distribution (referred to as older normal subjects). The body mass index (weight/ height ${ }^{2}$ ) was within the normal range both in the patients and in the normal subjects. In a separate and subsequent investigation we studied six healthy young subjects ("younger normal subjects"), also with a normal body mass index. Age, weight, and pulmonary function are shown in table 1 for the patients and the two groups of normal subjects.

\section{MEASUREMENTS}

Additional weight was provided by means of two leaded radiological gowns together weighing $10 \mathrm{~kg}$. This represented for the patients a mean increment in body weight of $15 \%$ (SD $2 \%$ ). Spirometric volumes were measured both with and without the additional weight, a bellows spirometer (Vitalograph) being used; the highest of three measurements of FEV and VC was used in the analysis. Exercise performance was assessed by means of the six minute walking test, ${ }^{5}$ performed along a level, enclosed hospital corridor, and a symptom limited, paced step climbing test during which a $25 \mathrm{~cm}$ platform was mounted every four seconds to a maximum of 150 steps. ${ }^{6}$ Ventilation and $\dot{\mathrm{VO}}_{2}$ were measured during stepping in the patients and older normal subjects while they were wearing a nose clip and expired gases were collected through a two way mouth piece (PK Morgan). Ventilation was derived from the concentration in mixed expired gas of argon, introduced at a known and constant flow rate into the expirate.' Oxygen consumption was calculated from $V_{E}$ and the difference between inspired and mixed expired concentrations of oxygen with a correction for the effect of the respiratory exchange ratio. A microprocessor and printer coupled

Table 1 Lung function, age, and weight of the patients and normal subjects (mean (SD) values with range in square brackets)

\begin{tabular}{|c|c|c|c|}
\hline & \multirow[b]{2}{*}{ Patients } & \multicolumn{2}{|c|}{ Normal subjects } \\
\hline & & Older & Younger \\
\hline $\begin{array}{l}\text { Age (y) } \\
\text { FEV }(1) \\
\text { (\% pred) }\end{array}$ & $\begin{array}{l}61 \cdot 1(8 \cdot 0) \\
1 \cdot 23(0 \cdot 5) \\
41(17) \\
{[17-79]}\end{array}$ & $\begin{array}{c}58 \cdot 7(9 \cdot 2) \\
3 \cdot 8(0.5) \\
114(12) \\
{[94-126]}\end{array}$ & $\begin{array}{c}29 \cdot 2(2 \cdot 5) \\
4 \cdot 8(1 \cdot 1) \\
110(14) \\
{[90-128]}\end{array}$ \\
\hline $\begin{array}{l}\text { VC (l) } \\
\text { (\% pred) }\end{array}$ & $\begin{array}{l}2 \cdot 94(0 \cdot 6) \\
77(17) \\
{[51-107]}\end{array}$ & $\begin{array}{l}4.81(0.5) \\
110(10) \\
{[95-125]}\end{array}$ & $\begin{array}{l}5.9(1 \cdot 3) \\
111(14)\end{array}$ \\
\hline $\begin{array}{l}\text { Weight (kg) } \\
\text { Body mass index }\end{array}$ & $68 \cdot 8(9 \cdot 2)$ & $67 \cdot 8(7 \cdot 3)$ & $68.2(6 \cdot 7)$ \\
\hline$\left(w t / h t^{2}\right)^{*}$ & $22 \cdot 3(2 \cdot 7)$ & $22.0(1.6)$ & $22 \cdot 3(0 \cdot 7)$ \\
\hline
\end{tabular}

*Normal range 19-25. to a mass spectrometer (Airspec 2000) updated values for $\overrightarrow{V E}$ and $\hat{V}_{2}$ every 20 seconds during stepping (Airspec 2400 metabolic system).

\section{PROTOCOL}

The patients and older normal subjects attended the laboratory on two occasions. At one visit the subject performed three six minute walking tests and at the other visit four step tests. The first walking test and the first two attempts at the stepping test were to allow familiarisation with the procedure and were not used in analysis. So that the improvement in performance that occurs with repeated testing ${ }^{6}$ would not influence the results, alternate patients entering the study wore the additional weight for the penultimate attempt at each type of exercise and the others wore it for the final attempt.

A subsidiary study was performed in the younger normal subjects to assess the effect of the additional weight on $\dot{V}$ and $\dot{\mathrm{VO}}_{2}$ during walking. Each performed two six minute walking tests (one with and one without the leaded aprons) on a treadmill at $5.6 \mathrm{~km} / \mathrm{h}$ and zero incline; the speed was chosen to be approximately equivalent to the level corridor walking speed of the patients. Ventilation and $\mathrm{V}_{2}$ were measured as previously described.

\section{ANALYSIS}

The numbers of steps climbed by the patients (fig 1) were compared by Wilcoxon's rank sum test for paired data. The values of $\dot{V} E$ and $\dot{V}_{2}$ with and without the added weight (fig 2) were compared by a two way

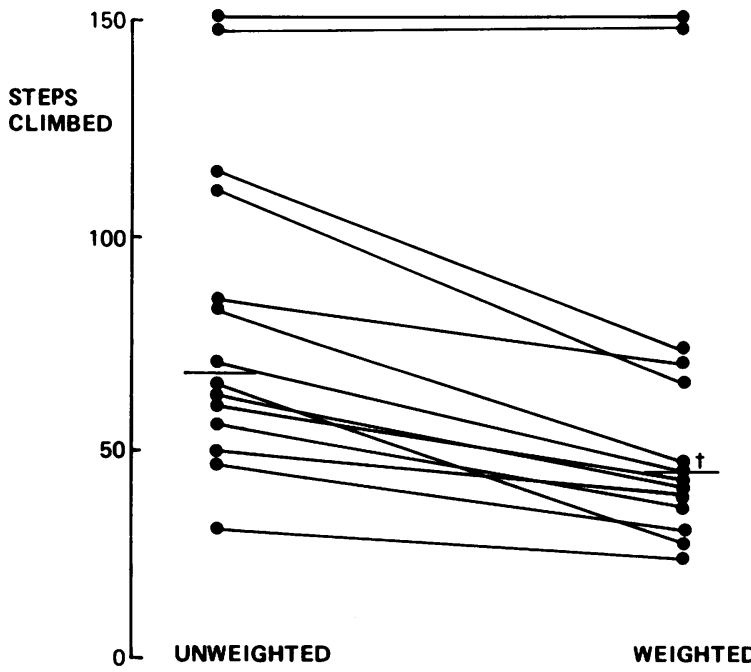

Fig 1 Number of steps climbed by individual patients with and without the additional weight. The bars denote the median. $\dagger p<0.01$ in the comparison of values for weighted and unweighted exercise. 

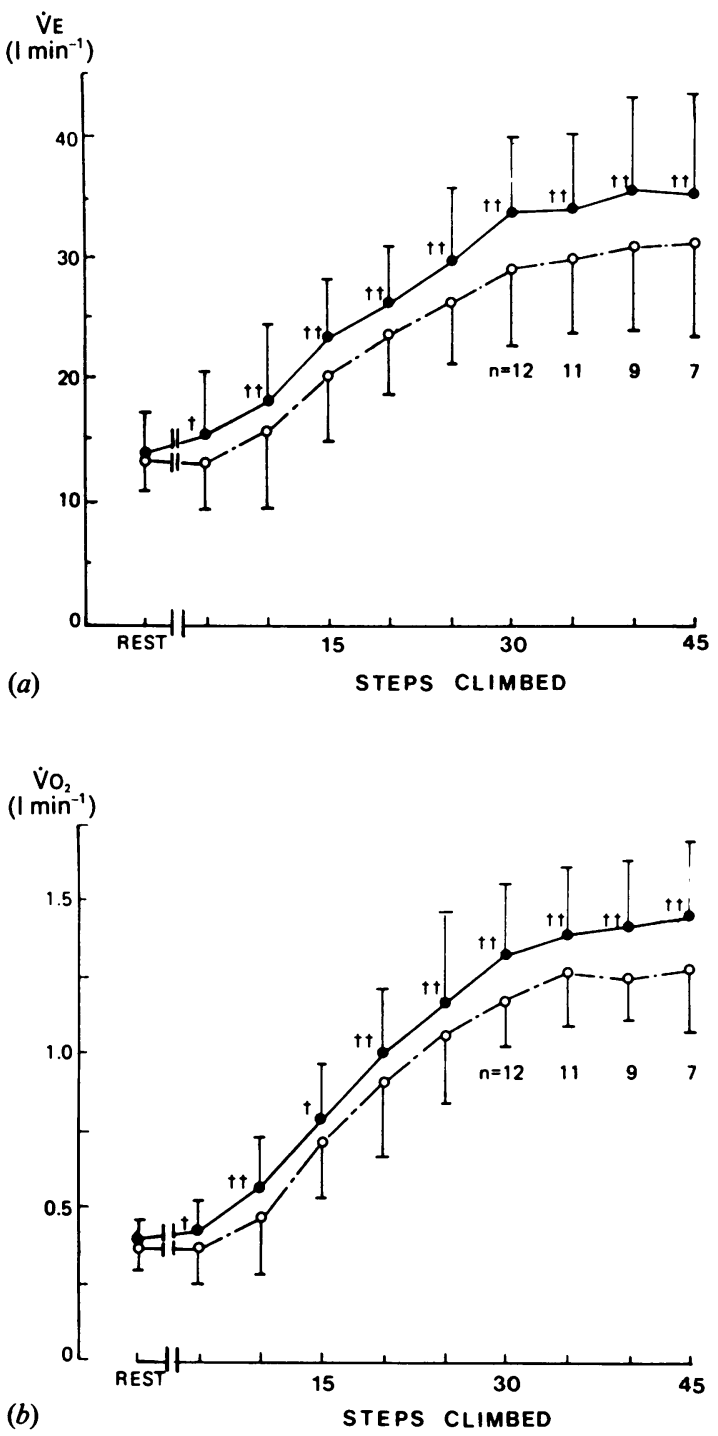

Fig 2 (a) Ventilation ( $\dot{V} E$ ) and (b) oxygen consumption $\left(\mathrm{VO}_{2}\right)$ at rest and during the first three minutes of stepping in the patients with $(\bigcirc)$ and without $(O)$ the additional weight (means with standard deviations). $n$ denotes the number of patients remaining during both weighted and unweighted tests after the relevant number of steps. $\dagger p<0.05 ; \dagger \dagger p<0.01$ in the comparison of values for weighted and unweighted exercise.

analysis of variance and Student's $t$ test for paired data. Differences between other sets of paired data were analysed by Student's $t$ test.

\section{Results}

EFFECT OF ADDED WEIGHT ON SPIROMETRY AND EXERCISE PERFORMANCE IN PATIENTS WITH CHRONIC OBSTRUCTIVE AIR WAYS DISEASE $\mathrm{FEV}_{1}$ and VC were not altered by the additional is weight but there was a small reduction in six minute $\vec{\circ}$ walking distance (mean \% fall 2.4 (3.9); p < 0.05; table 2).

In the stepping study two patients were able to complete 10 minutes of stepping (150 steps) both without and with the added weight; the other 12 patients showed a substantial reduction in the number $c$ of steps climbed. Overall, the median number of steps climbed was 67.5 without the extra weight and 44.5 with the weight ( $\mathrm{p}<0.01$; fig 1$)$.

EFFECT OF ADDED WEIGHT ON VENTILATION AND OXYGEN CONSUMPTION

\section{Patients}

At rest there was no change in either $\dot{\mathrm{VE}}$ or $\dot{\mathrm{VO}}_{2}$ as a result of wearing the added weight (table 2) but after a given number of steps climbed VE was $14 \%$ greater on average and $\dot{\mathrm{VO}}_{2} \quad 13 \%$ greater (fig $2 a$ and $2 b$ ). The maximum levels of $\hat{V}_{E}$ and $\dot{V}_{2}$ achieved at the abandonment (or, in two patients, termination) of stepping were, however, similar during unweighted and weighted exercise (table 2).

There were no significant correlations between percentage increase in body weight and increase in

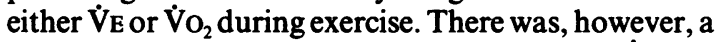
significant correlation between the increases in $\dot{V} E$ and $\mathrm{VO}_{2}$ during exercise that resulted from carrying the extra weight $(r=0.83, p<0.01)$.

\section{Normal subjects}

All six older normal subjects were easily able to complete 150 steps both without and with the added weight. As in the patients (fig 2), ventilation and $\mathrm{Vo}_{2}$

Table 2 Effects of weight on spirometric values and exercise performance in the patients (mean (SD) values except where specified otherwise)

\begin{tabular}{lcc}
\hline & Unweighted & Weighted \\
\hline FEV $(1)$ & $1.24(0.49)$ & $1.25(0.5)$ \\
VC(1) & $3.01(0.65)$ & $3.03(0.66)$ \\
6MWD (m) & $554(61)$ & $540(62)^{*}$ \\
Steps climbed (median) & 67.5 & $44.5 * *$ \\
VE resting $\left(1\right.$ min $\left.^{-1}\right)$ & $13.2(2.6)$ & $13.9(3.6)$ \\
Vo, resting $\left(1\right.$ min $\left.^{-1}\right)$ & $0.37(0.07)$ & $0.39(0.08)$ \\
Maximum VE $\left(1\right.$ min $\left.^{-1}\right)$ & $36.8(8.6)$ & $37.3(10.2)$ \\
Maximum Vo $\left(1\right.$ min $\left.^{-1}\right)$ & $1.35(0.27)$ & $1.41(0.35)$ \\
\hline
\end{tabular}

* $p<0.05 ;{ }^{* *} p=0.01$ when compared with unweighted.

FEV 1 - forced expiratory volume in one second; VC - vital capacity; 6MWD-six minute walking distance; $\mathrm{VE}$ - ventilation; $\mathrm{VO}_{2}$ oxygen consumption. 


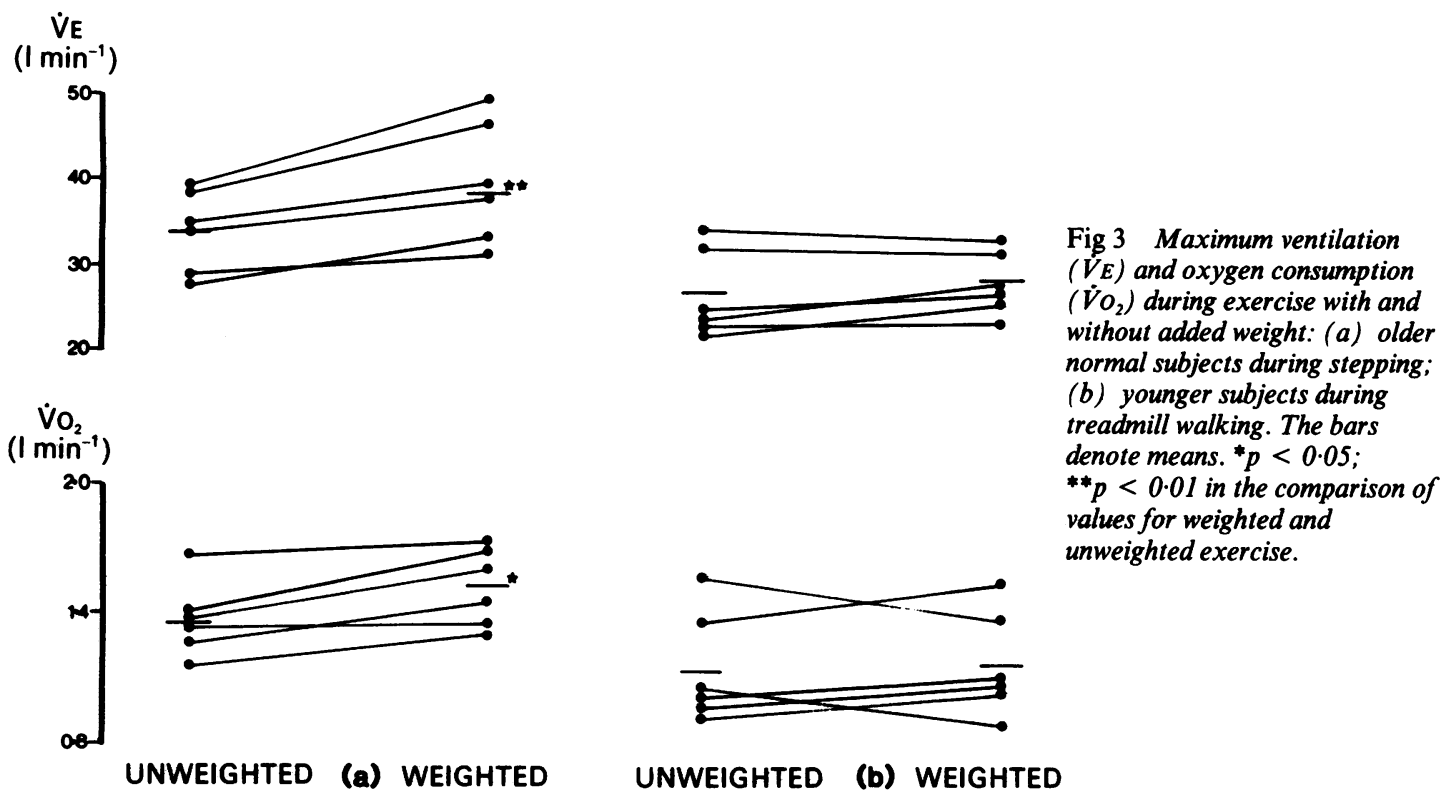

were significantly increased throughout weighted stepping. Unlike the patients, however, they attained maximum values of each that were greater after weighted than after unweighted stepping (fig $3 a$ ).

In the younger normal subjects undergoing level treadmill walking, however, there were no differences in $\dot{V} E$ or $\hat{V}_{2}$ during or at the end of exercise with and without the additional weight (fig $3 b$ ).

\section{Discussion}

This study has shown that the acute addition of $10 \mathrm{~kg}$ to a group of patients with chronic obstructive airways disease substantially impaired their ability to perform simple "uphill" exercise but had little effect on their level walking speed. Ideally, the effect of additional weight in patients with respiratory disease would be best studied by examining the consequences of natural weight gain (ethically difficult) or loss (practically difficult in a cohort of patients). There are reports of the effect of natural weight gain ${ }^{4}$ and $\operatorname{loss}^{8}$ in healthy individuals but no such data are available in patients with chronic obstructive airways disease. The results obtained in this study with artificially simulated weight gain may not be directly comparable to the effects of natural weight gain because obesity, in addition to its effects on $\dot{\mathrm{VE}}$ and $\dot{\mathrm{VO}}_{2}$ during exercise, may also influence respiratory mechanics, lung volumes, and gas exchange and the cardiorespiratory response to exercise. There is also evidence that cardiovascular fitness, assessed by oxygen pulse, may even be increased in the obese. ${ }^{9}$ Normal subjects have, however, been found to show effects of externally applied additional weight that are quantitatively similar to the effects of natural weight gain on $V_{E}$ and $\mathrm{V}_{2}$ during uphill treadmill walking. ${ }^{4}$

The lead gowns used in this study were associated with mild discomfort, principally heat, during exercise. Although the gowns rather than the weight itself might have reduced performance in the step test, this is unlikely as the same gowns had a minimal effect on the patients' ability to walk on the level and spirometric volumes (at rest) were unaltered. Furthermore, the patients achieved similar levels of ventilation at the end of the weighted and unweighted step tests, so the gowns are most unlikely to have materially impeded their ability to breathe.

In both the patients and the normal subjects $\dot{V} E$ and $\dot{\mathrm{VO}}_{2}$ were increased during stepping because the additional weight was being moved against gravity. The weighted normal subjects were still able to complete the stepping test with higher maximum values of $\dot{\mathrm{VE}}$ and $\mathrm{Vo}_{2}$. Although the patients attained similar final levels of $\mathrm{VE}_{2}$ and $\dot{\mathrm{VO}}_{2}$ with and without the weight, the number of steps they were able to climb was substantially reduced by the added weight, presumably because they were already reaching maximum $\dot{V}_{E}$ at the break point of stepping in the unweighted state, where their level of performance was on average already less than half of what would be expected in a group of healthy subjects of this age. ${ }^{6}$ Despite the pronounced effect of added weight on the steps climbed by the patients, the reductions in the six minute walking distance were slight. Because of the 
nature of the equipment used we were unable to measure $\mathrm{VE}$ and $\mathrm{VO}_{2}$ during corridor walking. For this reason a small group of young, healthy subjects was subsequently studied during level treadmill walking in an attempt to explain the observation that in the patients added weight had a minimal effect on performance in the walking test. Neither $\dot{\mathrm{V} E}$ nor $\dot{\mathrm{VO}}_{2}$ was increased with additional weight. If the same is true of the patients this explains the minimal effect on their six minute walking distance. The different effects of additional weight on level and uphill exercise are commonly observed in clinical practice, exercise tolerance on hills and stairs being more readily impaired than performance on the level.

Natural weight loss inevitably means the loss not only of fat but also of muscle bulk, which in the absence of cardiorespiratory disease would be expected to be associated with a reduction in $\mathrm{VO}_{2}$ max in healthy individuals. In patients with chronic obstructive airways disease, in whom exercise is limited by pulmonary mechanics, the expected small loss of muscle bulk seems unlikely to compromise an already reduced effort tolerance.

In conclusion, this study has shown that a small, acute increase in body weight may substantially worsen an already reduced exercise tolerance in patients with chronic obstructive airways disease. Most physicians would advise loss of weight in visibly obese patients with respiratory disease, but the results from this study suggest that even modest weight loss might benefit patients with symptomatic chronic obstructive airways disease even though they may be only slightly above their ideal body weight.

\section{References}

1 Johnson MA, Woodcock AA, Geddes DM Dihydrocodeine for breathlessness in "pink puffers". Br Med J 1983;286:675-7.

2 Mitchell-Heggs P, Murphy K, Minty K, et al. Diazepam in the treatment of dyspnoea in the "pink puffer" syndrome. $Q J$ Med 1980;49:9-20.

3 Openbrier DR, Irwin MM, Rogers RM, et al. Nutritional status and lung function in patients with emphysema and chronic bronchitis. Chest 1983;83:17-22.

4 Hanson JS. Exercise responses following production of experimental obesity. J Appl Physiol 1973;35:587-91.

5 Butland RJA, Pang JA, Gross ER, Woodcock AA Geddes DM. Two-, six-, and twelve-minute walking tests in respiratory disease. $\mathrm{Br}$ Med $\mathrm{J}$ 1982;284:1607-8.

6 Swinburn CR, Wakefield JM, Jones PW. Performance, ventilation and oxygen consumption in three different types of exercise test in patients with chronic obstructive airways disease. Thorax 1985;40:581-8.

7 Davies NJH, Denison DM. The measurement of metabolic gas exchange and minute volume by mass spectrometry alone. Respir Physiol 1979;36:261-7.

8 Farebrother MJB. The effect of weight loss by therapeutic starvation on respiratory function and pulmonary gas exchange in severe obesity. MD thesis, University of Cambridge, 1977.

9 Farebrother MJB. Respiratory function and cardiorespiratory response to exercise in obesity. $\mathrm{Br} \mathrm{J} D$ is Chest 1979;73:211-29. 